7 Письмо ФНС России от 14 марта 2012 г. № ЕД-4-3/4270 [Электронный ресурс] URL: https://www.garant.ru/products/ipo/prime/doc/70048294/

8 П. 3.1 ст. 170 Налоговый кодекс Российской Федерации [Электронный ресурc] URL: http://www.consultant.ru/document/cons_doc_LAW_28165/7e99d9a14446e1adf556f812066034a9091e0cc4/

9 Постановление Пленума ВАС РФ от 12 октября 2006 г. № 53 "Об оценке арбитражными судами обоснованности получения налогоплательщиком налоговой выгоды"

\title{
TAX CONSEQUENCES OF COMPANY REORGANIZATION IN SPIN-OFF FORM
}

\author{
(C) 2020 Popova Elena Evgenevna \\ Candidate of Economics Sciences, Associate Professor \\ (c) 2020 Bechikova Irina Evgenievna \\ Student \\ Samara State University of Economics. \\ E-mail: alpopowa@mail.ru, bechikova.irina@gmail.com
}

Keywords: reorganization, spin-off, business, taxation, tax consequences.

Reorganization in spin-off form has been studied. The advantages and disadvantages of the spinoff procedure and the tax consequences for enterprises operating under various tax regimes are considered.

УДК 338

Код РИНЦ 06.00.00

\section{УГРОЗЫ РАЗВИТИЯ ИСКУССТВЕННОГО ИНТЕЛЛЕКТА В УСЛОВИЯХ ЦИФРОВОЙ ЭКОНОМИКИ}

\author{
(C) 2020 Попова Екатерина Сергеевна* \\ студент \\ Самарский государственный экономический университет \\ E-mail: popovaks07@yandex.ru
}

Ключевые слова: искусственный интеллект, угрозы, цифрровая экономика, робототехника, законодательные инициативы.

В наши дни искусственный интеллект становится важным фактором прогресса цифровой экономики государства. Однако степень неоднозначности искусственного интеллекта и возможные угрозы от его внедрения порождают серьезные вопросы и требуют правовых гарантий безопасного функционирования систем искусственного интеллекта. В статье анализируются возможные угрозы, степень освоения и развития современного искусственного интеллекта в мире, а также рассматриваются отдельные законодательные инициативы по регулированию нового направления. доцент.

* Научный руководитель - Измайлов Айрат Маратович, кандидат экономических наук, 
Искусственный интеллект (ИИ) - это любое аппаратное или программное обеспечение, работающие совместно, которые имитируют действие человеческого интеллекта. Решая задачи, ИИ может принимать множество решений, и некоторые из них могут нести в себе угрозу для человечества 1 .

ИИ - это технология с широким спектром воздействий, которая может вызвать такие проблемы, как:

- изменение структуры занятости;

- роль правового регулирования;

- неприкосновенность частной жизни и т.д.

Развитие искусственного интеллекта может повлечь за собой глобальные последствия для экономической безопасности, социальной стабильности государственного управления и управления во всем мире.

При быстром развитии искусственного интеллекта нужно придавать особое значение рискам, угрозам безопасности, которые могут наступить в будущем. А также, разработать рекомендации по их предотвращению и ограничению, снизить вероятность рисков и обеспечить надежную разработку искусственного интеллекта.

Ведущие мировые державы, в том числе и Россия, начали реализовывать национальные стратегии активного развития ИИ. Например, 10 октября 2019 года В.В. Путин подписал указ "О развитии искусственного интеллекта в РФ". Утверждается национальная стратегия развития ИИ до 2030 года, а также гарантируется выделение финансов, в том числе на:

- прикладные и фундаментальные научные исследования;

- разработку процессоров;

- разработку опенсорсного ПО (открытое программное обеспечение) $)^{2}$

США хотят занять лидирующие позиции в исследованиях и использовании ИИ для создания кибероружия. Активно развивается в этом направлении и Китай. Там ИИ рассматривается как инструмент социального управления. Но в Европе и в Северной Америке разработчики ИИ опираются на более широкую базу, чем в Азии. В Итоге список 15и глобальных лидеров возглавили США, второе место занял Евросоюз (27 стран), третье место за Китаем. Важно заметить, что по числу стартапов, разрабатывающие различные виды ИИ, европейцы (а это около 730 фирм) отстают от американцев (1400 фирм), но опережают КНР (400 фирм)3.

С одной стороны, внедрение технологий ИИ может предоставить государству экономические преимущества с помощью увеличения эффрективности производства, обеспечить превосходства в различных видах вооружений, безопасность и усилить научный потенциал.

Но, с другой стороны, ИИ имеет не только выгоды, но и угрозы, причем угрозы всеобщего масштаба. В частности, если ИИ будет концентрироваться в руках только одной из держав. Это может привести к информационной войне и кибервойне. Также серьезные угрозы таят и ошибки при создании ИИ, а также просто неготовность к его внедрению4.

Заметны угрозы ИИ в информационной сфере и киберпространстве. Искусственный интеллект возможно будет способен создавать "fake news", искусственную реальность в режиме online, размещать неправдивую информацию на сайтах Центробанках, 
правительств государств, взламывать видеоконтент в телепередачах, аккаунты в социальных сетях, распространять информацию для влияния на сознание людей и заставлять их принимать "нужные" решения5.

Учитывая все вышесказанное, можно выделить 4 варианта, при которых ИИ представляет опасность:

1. ИИ создается для уничтожения

Эта машина включает: оружие с элементами ИИ и работает сама по себе. Беспилотники, которые используют поисковые системы, идентификации и ликвидации людей, которые попадают под признаки, заданные при их программировании (цвет техники, военная форма и т.п.). Такой системе будет безразлично, ребенок или гражданский объект - она выполнит поставленную задачу. Только представьте ситуацию, когда абсолютно любой человек сможет купить в магазине беспилотник, сделать его оружием, дать любую задачу, и отпустить?

2. Дружелюбный ИИ для злоумышленников

Сегодня ИИ входит во многие сферы жизни. Например, системы имитации голоса, которые могут оцифровать тембр голоса, произношение, и имитировать его. Это может быть использовано злоумышленниками, по образцу они подделают голос любого человека, после чего обманут его родных и близких с целью наживы.

3. ИИ, который неправильно нас поймет

Предположим, ИИ, созданный учеными для обеспечения безопасности, начнет обучаться по видеороликам с YouTube, выпускам новостей или по комментариям. После того, как он принял огромное количество данных, описывающих убийства, ограбления, военные конфликты он может решить, что люди представляют наибольшую опасность и попробует остановить все вышеописанное для нашей же безопасности.

4. ИИ, которого не поймем мы

А что, если появится искусственный интеллект, который обгонит людей так сильно, что мы не сможем его понимать? Если мы не сможем повлиять на его действия? Последствия представить трудно.

В будущем появится множество других примеров плохого использования ИИ, и нам действительно стоит этого опасаться.

Исходя из этого, можно утверждать, что в условиях формирования цифровой экономики можно наблюдать неэффективность современных правовых механизмов регулирования использования современных цифровых технологий. Последние вынуждают право меняться и взаимодействовать с другими регуляторами, для создания безопасного поля их использования.

Одним из первых в мире в Южной Кореи в 2008 году был принят Закон "О развитии и распространении умных роботов". Анализ мирового опыта говорит о том, что пока существуют тенденции конкретного регулирования вопросов, которые связанны с использованием роботов.

Так в Эстонии в 2017 году были приняты нормы об использовании курьеровроботов ${ }^{6}$.

В Германии в 2017 году Бундестагом были внесены изменения в Закон о дорожном движении Германии, где официально разрешается эксплуатация автомобиля посредством полностью автоматизированного вождения. 
В Китае происходит активное развитие технологий ИИ, появились законопроекты об использовании беспилотного транспорта и автоматизации процессов управления ИИ.

В РФ готовится проекты по регулированию использования беспилотных транспортных средств, разработаны проекты внесения изменения в транспортные кодексы. В Министерстве промышленности и торговли разработали правила для проведения испытаний в России беспилотных автомобилей на дорогах общего пользования в Татарстане и Москве с 1 марта 2019 г. по 1 марта 2022 г. Предполагается создание специального реестра беспилотных транспортных средств, а также введение в него ИИ для его регулирования 7.

Таким образом, анализ развития ИИ, угроз и законодательных инициатив, свидетельствует о постановке задач разными государствами как по решению наиболее актуальных вопросов, связанных с применением ИИ и робототехники, так и по глобальному определению дальнейшего системного анализа и регулирования использования ИИ в разных сферах жизни и необходимости обеспечения системы безопасности как отдельной личности, так и общества и государства в целом от угроз выхода ИИ из - под контроля человека.

1 М. Тегмарк Жизнь 3.0: быть человеком в эпоху искусственного интеллекта [Электронный pecypc] // Kindle для чтения электронных книг URL: https://proglib.io/p/ai-and-datascience

${ }^{2}$ A. Ализар Путин подписал указ о развитии искусственного интеллекта в РФ // [Электронный ресурc] // URL: https://habr.com/ru/news/t/471144

3 Е. Абрамова Самые перспективные ИИ - стартапы [Электронный ресурс] // VC.ru URL: https://vc.ru/finance/52042-samye-perspektivnye-ii-startapy

${ }^{4}$ И. Братко Пролог программирования для искусственного интеллекта; Williams-M., 2016 - 640 c.

${ }^{5}$ Х. Д. Мохаммад Искусственный интеллект и будущее труда: симбиоз человека и ИИ в принятии организационных решений // В.Н. 61(4),2018 - 539 с.

6 Э. Нестор Исследовательский центр проблем регулาиирования робототехники и искусственного интеллекта // [Электронный ресурc] // URL: http://robopravo.ru/estonskii_zakon_o_robotakhkurierakh

${ }^{7}$ А. Ализар В Госдуму внесен законопроект о беспилотных автомобилях на дорогах общего пользования // [Электронный ресурс] // URL: https://habr.com/ru/news/t/454862/

\title{
THREATS TO THE DEVELOPMENT OF ARTIFICIAL INTELLIGENCE IN THE MODERN WORLD
}

\author{
C 2020 Popova Ekaterina Sergeevna \\ Student \\ Samara State University of Economics \\ E-mail: popovaks07@yandex.ru
}

Keywords: artificial intelligence, threats, digital economy, robotics, legislative initiatives.

Today, artificial intelligence is becoming an important factor in the progress of the digital economy of states. However, the ambiguity in the development of artificial intelligence, possible threats from its use, raise questions and require legal guarantees for the safe functioning of artificial intelligence systems. The article analyzes the modern development of artificial intelligence in the world, individual legislative initiatives in the Russian Federation and abroad to regulate it, as well as possible threats to development. 